4 Wieclaw J, Agerbo E, Mortensen PB, Burr H, Tüchsen F, Bonde JP. Psychosocial working conditions and the risk of depression and anxiety disorders in the Danish workforce. BMC Public Health 2008; 8: 280.

5 Schernhammer ES, Colditz GA. Suicide rates among physicians: a quantitative and gender assessment (meta-analysis), Am J Psychiatry 2004; 161: 2295-302.

6 Kumar S, Hatcher S, Huggard P. Burnout in psychiatrists: an etiological model. Int J Psychiatry Med 2005; 35: 405-16.

7 Åkerstedt T, Kecklund G, Gillberg M. Sleep and sleepiness in relation to stress and displaced work hours. Physiol Behav 2007; 92: 250-5.
8 Ahola $\mathrm{K}$, Virtanen $\mathrm{M}$, Honkonen $\mathrm{T}$, Isometsä E, Aromaa A, Lönnqvist J. Common mental disorders and subsequent work disability: a populationbased Health 2000 Study. J Affect Disord 2011; 134: 365-72.

9 Levi L. The European Commission's guidance on work-related stress and related initiatives: from words to action. In Stress and Quality of Working Life: Current Perspectives in Occupational Health (eds AM Rossi, PL Perrewé and SL Sauter): 167-82. Information Age Publishing, 2006.

10 Gilbody S, Bower P, Rick J. Better care for depression in the workplace: integrating occupational and mental health services. Br J Psychiatry 2012; 200: $442-3$

\title{
On Asylums: Essays on the Social Situation of Mental Patients and other Inmates, by Erving Goffman
}

\section{Nick Bouras}

Erving Goffman's Asylums was first published in 1961 and a revised edition, with an extended introduction by William Helmreich, appeared in 2007.

Goffman, a Canadian sociologist born to Ukrainian immigrants, studied chemistry at the University of Manitoba before moving to the University of Chicago to continue in sociology. He became an expert on human interaction and is considered one of the most influential sociologists of the 20th century. The micro-interactions between patients and staff were a focal point of the book, which illuminated in a unique and perceptive way the social context created by St Elizabeth's, a 7000-bed psychiatric hospital in Washington DC, and its effects on patient experience and behaviour. The emphasis was on the patient's social world whereas all previous research on mental hospitals emphasised the perspectives of psychiatrists.

The book is divided into four essays based on Goffman's ethnographic study of St Elizabeth's. The first essay deals with 'total institutions' and is considered a classic in the psychiatric literature. This is followed by the essay on the 'moral career of a patient', describing the change from the status of pre-patient to that of in-patient and considering the initial effects of institutionalisation on social relationships. In the third essay Goffman examines the daily routine of a psychiatric institution. Finally, he turns his attention to the 'medical model', especially the effects on the patient-psychiatrist relationship. Goffman thought that psychiatrists lacked a 'scientific understanding' of mental illness and routinely misunderstood the behaviour of their patients.

I first read Asylums in 1975, while I was working on my PhD thesis, under the supervision of Jim Watson and Tom Trauer at Guy's Hospital, studying the effects of the ward environment on the behaviour of psychiatric in-patients. Goffman's observations were rich, penetrating and insightful, examining intelligently the 'inmates', staff and the interactions between them. Specifically, Goffman demonstrated how total institutions strip individuals of their formal identity and then re-socialise them in the institution's routines. He argued that an equilibrium of various improper roles prevails within the system allowing the continuation of its function, irrespective of utility to the patient.

Over 50 years since their first publication, Goffman's essays on asylums continue to attract interest in psychiatry. In January 2011, this journal published an editorial by Seamus MacSuibhne ('Erving Goffman's Asylums 50 years on') drawing attention to their role in humanising patients and to patterns that dehumanise them. Goffman's essays accelerated understanding of the complexities of the physical and social environment affecting the behaviour of psychiatric patients, including beliefs, values, roles, policies, procedures and rules. He has been hugely influential and was perhaps the prelude to the ideological trends that followed and eventually prevailed in psychiatric practice. Deinstitutionalisation, community care, normalisation principles, advocacy, empowerment and recovery are some of the products of sparkling sociological and ideological views and, arguably, have had more impact on the care of patients with severe mental illness and intellectual disability than molecular genetic and neurobiological research in the period since Asylums was published.

The current dominance of neurobiological research perspectives notwithstanding, psychiatrists need to have a deeper understanding not only of brain function but also of social factors, the environment, relationships and culture. This classic is a good point to start and one hopes that work of similar quality will be published on the experience of patients today, in the era of neurobiology and community care. 